\title{
Research Paper: Community-Based Management Challenges in Disaster Risk Reduction: A Content Analysis in Iran
}

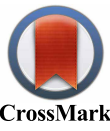

\author{
Seyed Hossein Hosseini ${ }^{1}$, Nasir Amanat ${ }^{1 *}$, Vahid Ghanbari ${ }^{2,3}$, Maryam Nakhaee ${ }^{4}$, Masoumeh Abbasabadi ${ }^{1}$, Mehdi Najafi ${ }^{2,5}$, Hamid Reza \\ Khankeh$^{1}$, Fatemeh Pashaei Sabet ${ }^{6}$ \\ 1. Research Center in Emergency and Disaster Health, University of Social Welfare and Rehabilitation Sciences, Tehran, Iran. \\ 2. Department of Health in Emergencies and Disasters, School of Public Health, Tehran University of Medical Sciences, Tehran, Iran. \\ 3. Institute of Public Health Research, Tehran University of Medical Sciences, Tehran, Iran. \\ 4. Social Determinants of Health Research Center, Birjand University of Medical Sciences, Birjand, Iran. \\ 5. Iran Hilal Applied Sciences Higher Educational Institute, Tehran, Iran. \\ 6. Department of Nursing, School of Nursing and Midwifery, Qom University of Medical Sciences, Qom, Iran.
}

Article info:

Received: 26 May 2016

Accepted: 9 Sep. 2016

Citation: Hosseini SH, Amanat N, Ghanbari V, Nakhaee M, Abbasabadi M, Najafi M, et al. Community-Based Management Challenges in Disaster Risk Reduction: A Content Analysis in Iran. Health in Emergencies and Disasters Quarterly. 2017; 2(2):63-70. https://doi.org/10.18869/nrip.hdq.2.2.63

: https://doi.org/10.18869/nrip.hdq.2.2.63

\section{Keywords:}

Challenge, Disaster risk management, Communitybased, Qualitative study

\section{A B S T RACT}

Background: The role of society and people in disaster risk management is prominent. However, using this potential and increasing the people's role have always been a challenge. The purpose of this study was to find community-based management challenges in disaster risk reduction.

Materials and Methods: This study was conducted with the qualitative approach and in the form of content analysis. Participants were selected purposefully and by snowball sampling out of 17 professors and managers in the field of incidents and disasters. Data were recorded and collected through semi-structured interviews. The records were transcribed and then analyzed.

Results: Results included 2 main themes of egocentrism and management helplessness (failure) and 5 main categories, including inadequate attention to the nature of the risk reduction process, inadequate community resilience, ignoring social capital, inadequate planning and training, and incorrect organization, as well as 13 subcategories.

Conclusion: Firstly, managers should accept the community as a major hub of the process to harness the power of community. Secondly, using capable and trained managers familiar with the concepts, literature, and challenges in the field of disasters increase participation of people in disaster risk management.

\section{Introduction}

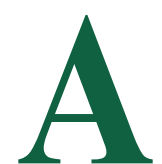

$\mathrm{t}$ the time of disasters, community members are directly influenced and hurt by large and small incidents $[1,2]$. Emergency response operations in these circumstances is beyond the responsibility of the governments and executing successful operations and reduction of losses by the authorities in organizations will be possible only through the group efforts of the society. Also good emergency management prevents the escalation of the urgent situations into disasters. In this regard, disaster risk management at the community level can be very appropriate and practical [3-5] in a way

* Corresponding Author:

Nasir Amanat, MSc.

Address: Research Center in Emergency and Disaster Health, University of Social Welfare and Rehabilitation Sciences, Tehran, Iran

E-mail: nasir23a@hotmail.com 
that efforts to encourage organizations and municipal bodies to take advantage of community-based approach have been made in urban management plans during recent years [6].

Because the locally-affected population of communities are the first responders who deal with initial provision of emergency services at the level of families and communities $[3,7]$, empowering them can significantly reduce the severity of losses [1]. Community-based disaster risk management approach results in building adaptation capacity, reducing the vulnerability of individuals and developing safer and more resiliency of most societies. It puts its focus from response phase to the activities planned in the prevention and reduction of disaster management cycle [3].

In this regard, community-based disaster risk management approach has been widely taken into consideration by national and international organizations and governments [8] in Southeast Asia during the past two decades [3]. Because Iran is among high-risk areas that every year witnesses a large number of natural hazards, using community-based management approach can decrease many consequences resulting from disasters. The results of Najafi et al. study in 2010 also indicate that people in big cities are greatly interested in the establishment of relief centers and participation in relief aids in the neighborhood [6]. However, Rafieian et al. in their study in 2013 with the aim of providing a framework to identify and analyze the social dimension of resilience to cope with the disaster showed that there was a significant relationship between how to manage and organize lasted group (volunteered emergency response neighborhoods) and cognitive and behavioral components of the disaster risk management [9].

Therefore, considering the importance of public participation in disaster risk management and also management of the existing capacities, the researchers designed this study to find obstacles, problems, and challenges of community-based disaster management.

\section{Materials and Methods}

This study was conducted by conventional content analysis method. The study population comprised middle managers, university lecturers and $\mathrm{PhD}$ students of Health in Disasters and Emergencies in Tehran. The study participants were selected using purposive and snowball sampling method. First, two managers and professors who had executive or scientific activities in the field of public participation in crisis management were chosen and asked to introduce other researchers who have the experience and knowledge about this topic.

The tool of collecting data in this study was semi-structured interviews in which after contacting the subject, the study objective was explained and if he or she declared willingness to participate in this research, any suggestion about the place and time of the interview was asked from the person. Before each interview, participants were assured that their words would be confidential and used as research data and if they do not wish to continue cooperation with researchers, they can opt out at any stage. All interviews were conducted in the proposed locations by the study participants. The average duration of each interview was 1 hour. By permission of the study participants, the interviews were recorded.

Interviews began with the question: "What is your opinion about the management of community-based disaster risk reduction?" The researchers, then, asked further supplementary questions and performed more probing and also took the necessary notes during the interview. Sampling process continued until data saturation. After interviews with 17 managers, teachers and students, theoretical saturation was reached when no new code, themes, and categories were found. Text of each interview was transcribed after listening several times to the words and they were studied several times by the researchers until achieving a general understanding of the interviews.

Eventually, the data were analyzed using content analysis in order to the check the content with interviewees. Next, the codes and themes were identified and main classes and themes were formed. In order to validate data credibility, two methods of prolong engagement of data and member check were performed and approval of process analysis in the study was carried out by someone else. To confirm the correlation of results, peer check method was used. Also, the verifiability of data was performed using Bracketing method, i.e., the researchers tried to abandon their opinions and thoughts at the time of interview and data analyses.

\section{Results}

Demographic information of 17 participants in the study included 5 managers, 8 members of the University Faculty and $5 \mathrm{PhD}$ and post-doctoral students of Health in Disasters and Emergencies. In addition, 5 interviewees were in a management and the faculty member positions simultaneously. Thirteen participants were men and the rest were women. 
Table 1. Obtained categories and subcategories

\begin{tabular}{|c|c|c|}
\hline \multirow{2}{*}{ Main Theme } & \multicolumn{2}{|c|}{ Main Categories and Subcategories } \\
\hline & Main Categories & Subcategories \\
\hline \multirow[t]{2}{*}{ Egocentrism } & $\begin{array}{l}\text { Insufficient attention to the nature of the } \\
\text { risk reduction process }\end{array}$ & $\begin{array}{l}\text { The need for promotion of community } \\
\text { participation } \\
\text { Ignoring the community as an important } \\
\text { part of the process of reducing the risk }\end{array}$ \\
\hline & Inadequate community resilience & $\begin{array}{l}\text { Insufficient attention to the issue of disaster } \\
\text { extra capacity } \\
\text { Capacity building for facing with danger }\end{array}$ \\
\hline \multirow{3}{*}{ Management helplessness (failure) } & Ignoring social capital & $\begin{array}{l}\text { Insufficient trust between the people and } \\
\text { officials } \\
\text { Ignoring the intellectual and social capital } \\
\text { Ignoring the hidden resources in the com- } \\
\text { munity }\end{array}$ \\
\hline & Inappropriate educational planning & $\begin{array}{l}\text { Emotional response to danger } \\
\text { Inadequate training needs assessment } \\
\text { Inappropriate and inadequate training }\end{array}$ \\
\hline & Inappropriate organization & $\begin{array}{c}\text { Uncertainty of responsibilities between } \\
\text { managers } \\
\text { Parallel organizations } \\
\text { Ineffective interagency communication and } \\
\text { information systems }\end{array}$ \\
\hline
\end{tabular}

The average work experience of participants in the field of crisis management was 8 years. After analyzing the obtained data, 5 main categories were found, which included "insufficient attention to the nature of the risk reduction process", "inadequate community resilience", "ignoring social capital", "bad training planning", and "inappropriate organization", also two themes as "distress management" and "egocentrism". In Table 1, the obtained categories and subcategories are shown. In the following, all categories and subcategories are explained through interview transcripts.

\section{Egocentrism}

(A): Insufficient attention to the nature process of the risk reduction

The findings suggest that community members are an integral part of the risk management process and whenever on element of the process is absent, that process will not yield any fruit and if disaster managers and planners ignore local community, they will lose chance of effective response to disasters [10]. Opinion of one of those interviewed was as follows:

"Risk management is a process and has various stages and if one component fails, the results will not be obtained. And society is one of the important and fundamental pillars in the process, which ignoring its role will make this process incomplete".
1. The need for promotion of community participation: According to the respondents, local people are one of the elements of the management and rapid and correct response to disasters. Achieving this requires the participation of all involved organizations. In this regard, statements of one of the interviewees were as follows:

"For using the power of the people, participation of all institutions is required because this is a multifaceted and inter-agency affair and it is a saying that many hands make light work".

2. Ignoring community as an important part of the process of risk reduction: Participants believed that organizations must provide necessary information for the community and encourage community participation in disaster risk management. One of the interviewees that addressed this topic said:

"People should be encouraged for more cooperation and this understanding should be created in them that participation in disaster management can be very helpful and for creating this understanding, different methods can be used, including risk communication".

(B): Insufficient community resilience

One important aspect of resilience in incidents and disasters is community-based resilience which is not often 
taken into consideration by the authorities. For example, one of the interviewees (participants) stated that:

"If a community has necessary capacities to deal with an accident, its resiliency increases and incident is never converted into a disaster. But this capacity is not created unless managers pay attention to it and make necessary investments in the preparations stages".

1. Insufficient attention to the issue of post-disaster capacity: The study participants consider one aspect of extra capacity i.e., the human resource and their participation in community-based disaster management important and believed that militia can have a decisive role in the creation of meta-capacity. One of the participants mentioned:

"One of the very important aspects of extra capacity to which should be paid attention in proportion to the increase in demand for services in crisis is human resource or staff whose role in creating extra capacity has usually been ignored".

2. Insufficient capacity to deal with risk: The results showed that resiliency against disasters must be empowered and people play the key role in capacity building in the society. In talking with one of the participants, this was mentioned:

"Identifying potentials and capacity building is one indicator of a society's resilience and one important element for this purpose (which is often overlooked) is society and the people".

\section{Management helplessness (failure)}

\section{(A): Ignoring the social capital}

Based on the findings, social capital has several dimensions which using all of its dimensions in disaster management works is a solid and strong support for officials. Participants has mentioned one of the challenges of the society as ignoring this huge social capital. One of the participants described the importance of social capital as follows:

"No government in the world can claim that it can manage incidents, because we have some objective resources and some hidden resources. Resources in the country are mostly hidden because they are at people's disposal. When the community gets involved, $90 \%$ of the hidden resources become resources that can help in capacity building and resiliency".

1. Insufficient trust between the people and officials: According to study participants' opinions, trust is a two way process, creation of which between people and officials requires various organizations, passage of time, and previous experiences. And the mutual trust ensures community participation in an emergency situation. One of the participants said in this regard:

"The most important social capital is people's trust in their system and interest of people to their residence, our people's interest to their neighborhood has declined. Several years ago, our attachment to our neighborhood was high, we loved our neighborhood, our neighbors, our city, our country but now our place attachment has decreased and we lost our confidence in the system. And the most important social capital we need to think about is restoration of people's trust in government officials and increasing the spatial attachment and dependence of people. If these two happen, the problem is solved and then there are so many capitals and capacities".

2. Neglecting the intellectual and social capital: According to participants' opinions, officials should use intellectual and religious capacities of people in order to make optimal use of them in an emergency situation, because in their opinions, our religious beliefs are potential capacities in the country and many humane and humanitarian principles have a valuable place in our religious principles. This is an opportunity that must be seized. One of the participants in this case noted that:

"Our society is a religious society with religious beliefs and a lot of our religious principles are linked with morality, altruism and humanity. If we can employ this great religious capital in humanitarian and humane aids, many of the problems and obstacles in an emergency situations are solved and a national solidarity will be created".

3. Ignoring big hidden resources in the community: The findings suggest that in all four stages of disaster management, the role of the community is very prominent and using this potential in all stages can facilitate the work and improvement of the consequences. One of the managers refer to that in this way:

"Look! Community is a solution worldwide and the solution in Iran. When community enters, you actually increase response elements, improved mitigation, increased preparedness and reduced the recovery period".

\section{(B): Inappropriate training planning}

Participants believed that education was one of the most important avenues of public participation in the programs of reducing the risk of incidents. And because the human 
connection is diverse and changing, in order to achieve this, different tools should be used in incident training, including training courses in pre-school centers and kindergartens and business units, courses at the local level, mosques, houses of culture and short-term training methods such as seminars, presentations, and conferences.

1. Emotional response to danger: These findings suggest that people can show reasonable and appropriate reaction to incidents and disasters, when they have repeated an activity over and over again and have done it before. Otherwise, they cannot use the strengths within the community properly. One of the participants stated:

"Lack of proper and continuous training and periodic exercises causes the behaviors in the community and even in management level at the time of risk be emotional and these emotions prevent the correct use of capacities".

2. Improper training needs assessment: The results showed that to achieve educational goals and create motivation to participate in disaster risk reduction, appropriate training content should be prepared because the inappropriate content is like going devious which is usually neglected by the authorities. In one of the interviews it was mentioned that:

"In the past years, no responsible authority had appropriate educational content to encourage and enhance the motivation of the people to participate in risk reduction programs".

3. Inadequate and inappropriate training: To change behavior requires long-term training and long-term training requires long-term planning, which is, however, not practical due to administrative changes in the country. One of the professors of the University said:

"With the change of management in organizations, all programs, including training programs are completely altered but to change behavior a long-term plan and fundamental training is required".

\section{(C): Incorrect organization}

Emergency and disaster management has several phases which in each phase different organizations and institutions are responsible. In other words, a proper management requires participation of several organizations and interagency partnership will be effective when they all have a common goal. This is achievable only through partnership of all responsible organizations, supporters and partners. One of the participants pointed out this as follows:
"In all aspects and stages of risk management, interagency coordination is especially important and community-based management is not an exception".

1. The uncertainty of responsibilities between managers: According to participants' opinions, tasks, roles, and responsibilities are uncertain among the managers of an organization and in many occasions. Managers have appropriate communication devices and do not accept each other's policies or see their devices and their positions above the rest. In the words of one participant:

"Managers in different departments have no precedents and consensus over the role of community in risk management and for this reason, everyone plays his own instrument and look at the problem in his viewpoint".

2. Parallel organizations: The results showed that lack of division of labor and responsibility in an appropriate way caused interruptions with other organizations in some cases, and led to the duplicates and the waste of resources. People believed that with the creation of the division of labor and inter-agency coordination in the field of disaster, coordination would increase for the use of community as a strong arm in Disaster Management. In the words of one of the participants it is expressed as:

"In our country all are responsible for everything but at the same time many of the issues are without responsible and accountable authorities. For us to use people in this respect, a known entity should be specified because, otherwise, tasks are put on others' shoulders".

3. Ineffective inter-agency communication and information systems: It was believed that coordination needs communication system and effective inter-organization exchange of information. Lack of communication and organizational awareness about the actions and practices of each other are another obstacle to use community in the field of disaster management. One of the participants in the study mentioned that:

"When the various involved organizations in risk management have no effective communications and are not aware of the responsibilities and actions of each other, the result is that everyone thinks that it is the task of other organization or other entity should do such task".

\section{Discussion}

Themes found in this study included egocentrism and management failure. One of the main categories of themes are egocentrism, i.e., insufficient attention to the 
nature of the disaster risk reduction process. Participants had a census regarding risk reduction management as a process, which started from a point and has various components, and they consider the community as an important, necessary, and integrated part of this process. One of the themes extracted was organizational participation in a way that participants believed that for the attention of society and using its potential, all involved organizations should have an active role.

In Becky et al. study, the emphasis was made on the need for participation of various organizations in disaster management in form of identifying organizational contradictions so that an issue in a corporate is not an obstacle for other areas [11]. Based on the results of the study, existence of attitudes toward public participation (in different levels) are necessary in preparation, prevention and responding to possible incidents. Depending on the type, location, scope and extent of incident, and in general the conditions of its occurrence, the need to participation of indigenous individuals, people and resources varies.

Of other main categories of egocentrism was insufficient resiliency of the community. Resilience is described as the capacity of a system in returning to equilibrium after a movement. The word is also used to describe the capacity of individuals and society. And a resilient society means the communication process of implementing a set of adaptive capacity of a network towards the positive direction of performance and compatibility of the population after occurrence of an accident or the scourge that has physical, social, and psychological dimensions. To achieve community resilience, long-term capacity building from various aspects of society is needed [12].

In a study by John Hayek et al., issue of communitybased extra capacity has been referred to as follows: measures taken to provide health care services in responsive centers at the community level and these measures are taken with the cooperation and supervision of regional responsive centers and represent a public commitment to support and strengthen the health system [13]. Social capital, as a direct and indirect resource, is a by-product of social networks and social support systems among families, friends, and community members [14].

Social capital of communities reduces the pressure of the society. The opposite is also true meaning that the pressure on society suppresses social capital [15]. In Jahangiri et al. study, it was found that by creating contexts to empower members of the community, the potential power of people for compatibility with harmful consequences for the risks increases and it will lead to their contribution in the planning, organizing, policy making, coordinating and controlling all actions that result in reduction of the risk. In this way, the capacity of the population at risk to appropriately confront and deal with disasters increases [16].

Ranmuthugala et al. introduced identification of social capital, capacity building on the capital and recognizing its vulnerability as one of the pillars of the communitybased disaster risk management. They considered the use of social capital effective and important in decreasing economic costs and also the social effects of disasters [17]. Inappropriate training planning has been mentioned as another obstacle for community-based disaster risk reduction management in a way that lack of appropriate and principle teaching cause irrational and emotional response. They considered appropriate training as one of the most important ways of promoting public participation in disaster risk reduction programs. According to participants, it is an emotional, irrational and unconventional response when the person shows reaction only based on emotions and feelings regardless of income and labor complications, which generally results from lack of awareness and adequate training and is one of the obstacles.

In other studies an emphasis has been made on the issue of the influence of emotions and self-sacrifice of community on the Disaster Management, which leads to a lack of suitable capabilities and inconsistent response in disaster conditions and it was believed that proper education requires planning and appropriate needs assessment for education [18, 19]. In Setyowati, Burke, and Yousefi study, the emphasis was placed on the role of education in alluring community participation as well as the role of community training for creating empowerment and participation in emergency situations [20-22].

Today more than ever, managers should have the ability to make decisions quickly and accurately in an uncertain environment and successful managers adapt with strategies that rely on intuitive processes and tacit knowledge and are potentially supported by adapted emotional responses [23].

Among other subcategories mentioned are "poor training needs assessment" and "inadequate and inappropriate training". The participants believed that to achieve long-term educational goals, the planning and educational content are necessary for the target group, because lack of plan means going off road and losing resources. Huang et al. noted that to increase community role in risk management community skills a comprehensive and long-term training are needed [24]. Similarly, 
Veenema et al. recommended the necessity of having guidelines and educational content in the field of disaster training [25].

Another extracted theme was "wrong organizing", which participants believed that lack of harmony among different organizations can be an important factor in nonusage of community in disaster management. This result was obtained in Davis et al. study [26], too. Based on Becky et al. study, a general management framework with a control system and complex three-layer command system was created in England for better inter-agency coordination at the time of responding to disaster [11]. However, based on the results of Rezaei et al. study, duplicate activities are one of the problems in many organizations in Iran and especially the health sector which have several trustees and border of duties are not transparent. This leads to the fact that many tasks remain without trustee. Also they emphasized the existence of a single management in the various organizations to respond effectively to disasters [27].

In Raju and Davis study, they noted the exchange of information and the importance of communication system as one of the critical component of coordination [26, 28]. On the other hand, coordination is dependent on the existence of communication system and effective interagency exchange of information. Lack of communication and organizational awareness of the measures and practices of each other are another obstacles to use community in the field of disaster management.

\section{Conclusion}

In conclusion, our study showed that "management failure" and "egocentrism" are among the major obstacles in the optimal use of community in disaster risk reduction. To overcome these problems, holding training courses to empower people and beneficiaries and considering the importance of community, paying attention to the guidelines for public participation and gaining people's trust are essential elements in community-based risk reduction management.

Achieving these goals is possible through precise division of duties and promoting coordination among responsible agencies. By creating contexts to empower community members, the potential power of people for compatibility with the risks of harmful consequences increases and contribute them in the planning, organizing, policy making, coordinating and controlling all measures taken that lead to the reduction of risk. In this way, the capacity of the at risk population for proper confrontation and dealing with disasters increases.

\section{Acknowledgments}

Authors express their gratitude to all study participants and also President of the Center for Health Research of the Social Welfare Disaster and Rehabilitation University that had complete cooperation with us. This research did not receive any specific grant from funding agencies in the public, commercial, or not-for-profit sectors

\section{Conflict of Interest}

The authors declared no conflict of interests.

\section{References}

[1] Jahangiri K, Tabibi SA, Maleki MR, Alamdari Sh. [A comparative study of community-based disaster management in selected countries and provide a model for Iran (Persian)]. Payesh. 2009; 8(1):49-57.

[2] Jonkman SN. Global perspectives on loss of human life caused by floods. Natural Hazards. 2005; 34(2):151-75. doi: 10.1007/s11069-004-8891-3

[3] Salajegheh D, Pirmoradi N. Community-Based Disaster Risk Management (CBDRM) and providing a model for Iran. International Journal of Engineering Research and Development. 2013; 7(9):60-9

[4] Chen LC, Liu YC, Chan KC. Integrated community-based disaster management program in Taiwan: A case study of Shang-An village. Natural Hazards. 2006; 37(1-2):209-23. doi: $10.1007 /$ s11069-005-4669-5

[5] Allen KM. Community-based disaster preparedness and climate adaptation: Local capacity-building in the Philippines. Disasters. 2006; 30(1):81-101. doi: 10.1111/j.14679523.2006.00308.x

[6] Najafi M, Sepasi Moghadam H, Pourmohamad A. [Feasibility study of local relief centers in big cities (Persian)]. Journal of Rescue \& Relief. 2009; 1(2):23-29.

[7] Benedek DM, Fullerton C, Ursano RJ. First responders: Mental health consequences of natural and human-made disasters for public health and public safety workers. Annual Review of Public Health. 2007; 28(1):55-68. doi: 10.1146/annurev.publhealth.28.021406.144037

[8] Ostadtaghizadeh A, Ardalan A, Paton D, Jabbari H, Khankeh HR. Community disaster resilience: A systematic review on assessment models and tools. PLoS Currents. 2015. doi: 10.1371/currents.dis.f224ef8efbdfcf1d508dd0de4d8210ed

[9] Rafieian M, Motahhari ZS. [Designing a model for studying the community based disaster risk management approach Case Study: DAVAM Plan (Community emergency response 
volunteers) (Persian)]. Journal of Disaster Management. 2012; 1(1):5-12.

[10] Pearce L. Disaster management and community planning, and public participation: How to achieve sustainable hazard mitigation. Natural Hazards. 2003; 28(2-3):211-28. doi: 10.1023/a:1022917721797

[11] Hill B. Diagnosing co-ordination problems in the emergency management response to disasters. Interacting with Computers. 2010; 22(1):43-55. doi: 10.1016/j.intcom.2009.11.003

[12] Norris FH, Stevens SP, Pfefferbaum B, Wyche KF, Pfefferbaum RL. Community resilience as a metaphor, theory, set of capacities, and strategy for disaster readiness. American Journal of Community Psychology. 2007; 41(1-2):127-50. doi: 10.1007/s10464-007-9156-6

[13] Hick JL, Hanfling D, Burstein JL, De Atley C, Barbisch D, Bogdan GM, et al. Health care facility and community strategies for patient care surge capacity. Annals of Emergency Medicine. 2004; 44(3):253-61. doi: 10.1016/j.annemergmed.2004.04.011

[14] Hawkins RL, Maurer K. Bonding, bridging and linking: How social capital operated in New Orleans following Hurricane Katrina. British Journal of Social Work. 2009; 40(6):177793. doi: $10.1093 /$ bjsw/bcp087

[15] Mathbor GM. Enhancement of community preparedness for natural disasters the role of social work in building social capital for sustainable disaster relief and management. International Social Work. 2007; 50(3):357-69. doi: $10.1177 / 0020872807076049$

[16] Jahangiri K, Tabibi J, Maleki MR, Alamdari S. [A comparative study of community-based disaster management in selected countries and presenting a model for Iran (Persian)] Payesh. 2009; 8(1):49-57.

[17] Zwi A, Spurway K, Ranmuthugala G, Marincowitz R, Thompson L, Hobday K. Do Community Based Disaster Risk Management (CBDRM) initiatives reduce the social and economic cost of disasters? London: University of London. 2013.

[18] Sauer LM, Catlett C, Tosatto R, Kirsch TD. The utility of and risks associated with the use of spontaneous volunteers in disaster response: A survey. Disaster Medicine and Public Health Preparedness. 2014; 8(1):65-9. doi: 10.1017/ dmp.2014.12

[19] Barsky LE, Trainor JE, Torres MR, Aguirre BE. Managing volunteers: FEMA's Urban Search and Rescue programme and interactions with unaffiliated responders in disaster response. Disasters. 2007; 31(4):495-507. doi: 10.1111/j.14677717.2007.01021.x

[20] Yosefi Mojir K, Pilemalm S. A framework for "New Actors" in emergency response systems. Paper presented at: The $10^{\text {th }}$ International Conference on Information Systems for Crisis Response and Management (ISCRAM 2013), 2013 May 12-15, Baden-Baden, Germany.

[21] Burke R. Disaster education in South Los Angeles faithbased organizations: A pilot study to promote community preparedness and resiliency. Paper presented at: The $142^{\text {nd }}$ APHA Annual Meeting and Exposition. 2014 November 1519 , New Orleans, USA.

[22] Setyowati DL, Rachman M. Community based flood disaster education model to improve people's awareness to flood in Banjir Kanal Barat, Semarang Indonesia [Internet]. 2016 [Cited 2016 Septamber 3]. Available from: http://bappeda jatengprov.go.id/jarlitbangnov/index.php?ref=publication\& $\bmod =$ doc\&id $=2382$

[23] Sayegh L, Anthony WP, Perrewé PL. Managerial decisionmaking under crisis: The role of emotion in an intuitive decision process. Human Resource Management Review. 2004; 14(2):179-99. doi: 10.1016/j.hrmr.2004.05.002

[24] Huang B, Li J, Li Y, Zhang W, Pan F, Miao S. Need for continual education about disaster medicine for health professionals in China-a pilot study. BMC Public Health. 2011; 11(1):89. doi: 10.1186/1471-2458-11-89

[25] Veenema TG. Expanding educational opportunities in disaster response and emergency preparedness for nurses. Nursing Education Perspectives. 2006; 27(2):93-9. PMID: 16733973

[26] Davis LB, Samanlioglu F, Qu X, Root S. Inventory planning and coordination in disaster relief efforts. International Journal of Production Economics. 2013; 141(2):561-73. doi: 10.1016/j.ijpe.2012.09.012

[27] Rezaei Dolatabadi H, Khazaei Poul J, Kia Lashaki J, Amani M, Verij Kazemi R. [Developing a model regarding the influence of organizational culture on knowledge sharing and agility in future crisis management, a passive defense approach (Persian)]. Emergency Management. 2013; 2(3):57-65

[28] Raju E, Becker P. Multi-organisational coordination for disaster recovery: The story of post-tsunami Tamil Nadu India. International Journal of Disaster Risk Reduction. 2013; 4(1):82-91. doi: 10.1016/j.ijdrr.2013.02.004 